\title{
Intelligence, Globalization, Complex and Multi-Level Society
}

\author{
Antonella Colonna Vilasi* \\ Centro studi Uni, Rome, Italy \\ Email: mavil@tiscali.it
}

How to cite this paper: Colonna Vilasi, A. (2018). Intelligence, Globalization, Complex and Multi-Level Society. Open Journal of Political Science, 8, 47-56. https://doi.org/10.4236/ojps.2018.81004

Received: December 8, 2017

Accepted: January 14, 2018

Published: January 17, 2018

Copyright (C) 2018 by author and Scientific Research Publishing Inc. This work is licensed under the Creative Commons Attribution-NonCommercial International License (CC BY-NC 4.0). http://creativecommons.org/licenses/by-nc/4.0/

\begin{abstract}
The information activity is based on the security needs. National Security is a concept that refers to the idea of a Nation not only in purely ethnic terms of nationality but also in the wider sense of defense as a center for political, economic, social and cultural imputations. According to a simplistic vision of National Security, typical of an old constitutionalist doctrine, defense from external threats and the maintenance of internal order are of primary importance. In contemporary Nations, international and regional organizations, legal entities under international law and an ever-increasing international structure of international relations made the system unprecedented and complex. The concept of National Security involves all the activities, citizens and tangible and intangible assets, culture and cultural identity.
\end{abstract}

\section{Keywords}

Intelligence, Globalization, Complex Society, Politics

\section{Introduction}

After the end of the Cold War and with the fall of the Berlin Wall, following the Perestroika, the world has witnessed a series of epochal changes, particularly the end of an era that was characterized by the confrontation/clash between two opposing blocks.

The US-USSR bipolar system collapsed and a new world order settled; geopolitical balances are newly being put in question. With the nomination of Gorbachev at the summit of the USSR, the anti-system power, the one against which all

*Pioneer in Intelligence Studies in Italy, during the last 20 years the author's research interests focused on Intelligence, the relation with the Political Science and the Intelligence cycle. With more than 70 books published on the topics; among them: The Intelligence Cycle, The History of M16, The History of the CIA, The History of the Italian Secret Services, The History of the Entity, The History of Mossad, and The History of the STASI. 
"Western" alliances were formed, changed dramatically; the international framework radically changed and the Soviet new thinking brought in played relationships and strategies consolidated for decades.

When making choices, whether economical or military, it is a must to have a real modus vivendi, a habitus that allows perceiving the world as a decipherable set, a management philosophy and true science taking into account any data of the incalculable.

Nowadays the international system is in continuous and tumultuous transformation. One can even say that the real National system does not exist anymore, except as a part of the international one.

Management's culture has opened up new horizons by making it clear that quality is not just a matter of communication, technology but a true management philosophy, aimed at pursuing goals such as raising awareness levels and responsibility in the management of any activity and consequently of the resulting power.

The decision maker should be the one who overcomes the technical-administrative gaps; for example, in the public administration, identifying the lack of professionalism and technology to achieve effective forecasting, planning and control in order to get a fast circulation of the information has to be always integrated and easy to access.

\section{Research Questions}

With reference to this research, the first question posed is: how can Intelligence address the new challenges that we live every day, in computerized, multiethnic and multicultural societies, and above all in a globalized world?

Second question: what are the new capabilities and know-how that contemporary Intelligence needs in such a complex, turbulent and "chaotic" international system so as to require a new holistic and less systemic approach?

\section{Research Methods}

This study uses a three-step methodological approach: data collection, coding and analysis, using qualitative techniques.

The article offers a number of original contributions to the scientific literature.

First, it re-examines the sources and the theory-building and proposes alternatives to the referable scientific literature accepted and proposed by the majority of scholars.

It strengthens the holistic interrelations in terms of consistency between disciplines such as Intelligence studies, history, sociology, political geography, and political science.

Thirdly, the proposed mixed methods generate an agenda for possible future studies and researches.

The documents used are referring to open source documents, archives, publi- 
cations, and reliable secondary sources.

\section{Literature Review}

Academic studies, apart from the bibliography proposed in the article, refer mainly to Intelligence agencies' manuals for internal use, in particular to CIA manuals.

The international politics is post-international, as it is a policy that is no longer merely a matter of Nations, but rather of subsystems, a policy, consequently, turbulent, characterized by a strong sense of uncertainty.

Political turbulence implies a change of parameters, as the boundaries of the system can no longer contain fluctuations of the variables (Rosenau, 1990).

Moreover, just as in physics, it is a flow regime characterized by stochastic and random changes.

It is instable, it is characterized by random adjustments.

We live in computerized, multiethnic and multicultural societies, and above all in a globalized world; this makes the traditional statocentric system obsolete, unable to confront and adapt to the challenges of complexity and multicentricity.

Systemic interdependencies make the international system so complex, turbulent and chaotic to make a new approach to reality more holistic and less systemic.

The Cartesian paradigm, which guided the logic of power to the threshold of the new millennium, today shows all its inefficiency and inability to handle the uncertainty that is now the rule.

Newtonian mechanics and Cartesian linearity are not made to handle complexity.

Indeed, if you continue to handle complex processes with such old-fashioned tools, you risk, without any doubt, even without awareness, of renouncing to politics, that is the art of managing complexity and driving the change.

It is not about to control the "structural" complexity, but the "interactive" complexity. Social systems are open systems, not mechanisms or structures.

The subsystems are in internal relationship, not in external relation.

So-called unexpected events have become common cases and the only way to dominate change and overcome turbulence consists in the ability to learn and adapt to new situations.

This involves the use of analysis, Intelligence, forecasting and planning/programming, in one word, strategic analysis capabilities.

Such system escapes from any control, helped by an increasingly sophisticated technology; yet the need for Nations to control, prevent, analyze remains the sine qua non for the very survival of the system.

Political decision-makers and their ability to demonstrate familiarity with matters related to National Security and the use of targeted information for its safeguard, come into play; in the countries where this is put into common use, 
Intelligence agencies are recognized as a key role in the government system, which they integrate providing a continuous and concrete support to the political decision.

The post-bipolar era is characterized by complexity, and yet analysts must refine their methodological tools. In the case of an urgent and critical situation, the Cartesian causal principle, the systemic approach, which is apparently capable of providing all kind of solutions, takes its course.

However, the complexity of processes and the relationships of interdependence are such as to impede control over the already taken actions and over the predictability of their outcomes.

It is difficult to imagine that the international system (and, more generally, any social system) can have a well-defined macroscopic direction emerging from a chaotic molecular movement in systemic transformations.

For example, referring to international crises or revolutions, or even, international integration processes.

Only from a certain critical threshold, irreversible states can be produced. Before such threshold, the chaos can be re-absorbed by the previous order or the previous equilibrium.

And a systems' analysis applied to policy can determine energy levels that trigger irreversible processes.

The collapse of the Berlin Wall sanctioned the end of a world model. In opposition to unipolar globalization, the affirmation of a multipolar model became the major imperative of the great powers' foreign policy, which were ready to re-negotiate their power position.

The construction of a multipolar world can only be achieved through a system of strategic alliances.

The fall of the Berlin Wall was an event that has upset the world scenario.

The Intelligence suffered a rebound in the transition from a bipolar scenario to a multipolar or rather unipolar situation, given the preponderance of the US power.

The collapse of the Berlin Wall meant the need to deal with unprecedented situations.

A group of newly formed Nations, middle powers and so far satellites around the two big blocks, the USA and the URSS, provided new impetus to Intelligence activities in the incoming millennium. The so-called post-1989 polypolarism, in fact, polarized by the confrontation between the great powers, thus breathing on the classical geopolitical factors.

The events that marked the years between 1989 and 1991 changed the previous international scenario: a bipolar system, national interests, threats and risk factors affecting the National Security collapsed to undergo a complete metamorphosis with reference to the new multipolarism. Consequently, Intelligence activities had to adapt and adapt once again (Colonna Vilasi, 2013).

First and foremost, the disappearance of the Soviet Union and the end of the Warsaw Pact, which tied the US within the countries in its sphere of influence, 
deprived the West of the major direct military threat as well as the main ideological opponent.

At the same time, small and medium powers have partially rediscovered their sovereignty over a limited number of years and have seen their participation in the world's geopolitical reconstruction, having taken part in their defense and security issues, particularly in central and eastern Europe, in the Balkans and in the Middle and Far East.

Following a classical geopolitics based on a direct territorial domination and military instruments, such as the state-of the-art of World War II conflict, with a policy focused on acquiring and controlling new territories, in nowadays world the geo-economic aspects prevail, and the game is no longer so much the territorial control as the economical one.

The clash has therefore shifted to the battlefield of global trade, a new true confrontation area, with a reconfiguration of the power hierarchy and regulatory frameworks whose consequences, sometimes predictable, will be more significant than a war episode.

Once considered medium powers, Germany, Turkey and the People's Republic of China have entered the "G8 club", the elite of Nations capable of influencing the world and poles of economic and cultural policy aggregation.

The end of bipolarity has also caused more relevant long-term effects.

The Soviet Union, now almost cut off from the international community, in the past, in addition to being a superpower, was a stabilizing element within the dual system.

Systemic control and self-regulation capabilities strongly weakened, causing a dizzying increase in limited-type, regional and local conflicts.

Modelling international systems, highlight the structural differences between the various interaction links.

The past bipolarity, called elastic, characterized the scenario of post-war international relations, formed by two opposing blocks controlled by a superpower, respectively.

To characterize such a bipolarity, in addition to the two opposing blocks, and to the third of non-aligned neutral Nations, there were some supranational and transnational organizations participating to international relations and capable of influencing the relations between the antagonist poles.

The stalemate between the two controversial blocks was the arms race.

Having both a thermonuclear potential, one had to impose a direct connection between the perceptions and the reactions of the systemic components.

Any variation, though sensitive, in the war potential of one party affected the other and the whole system.

On the other hand, nuclear power ensured mutual deterrence and strengthened the need for stability and internal control. None of the two contenders could ever overcome the stall.

The minor actors, satellites of the bipolaristic system, could only act in a limited range of options: they had to negotiate rather than fight or just fight 
smaller wars, having to abstain from engaging in large-scale combats, in order to be prepared in the event of a crisis and a confrontation between the two superpowers.

The two opposing blocks, with their allies, formed a quasi-granite complex with long-term alliances based primarily on permanent interests and ideological reasons, and a defined nuclear MAD capability, Mutual Assured Destruction.

The word Intelligence used, and often abused, in spy stories such as novels and films, awakens in the mind something that has to do with mystery, international intrigue, espionage.

The English term, refers to a very precise action, or espionage, such as deciphering, translating and understanding the secrets of the enemy. It means creating an espionage apparatus, that, as a set of procedures and attack formats.

If we want to provide an explanation the most objective possible of the term Intelligence we can define it as the set of activities aimed at obtaining information relevant to National Security, whether a branch of the governmental activity, or a specific academic field dealing with international relations, foreign policy and national security.

Nevertheless, such activity is often confused with the police investigation, but the operational fields are different.

Police activities in the rule of law, in fact, are carried out openly and are aimed at acquiring objective elements, according to well-established procedures to be used in repression, all open and screenable.

Informational activities, on the contrary, as well as having no direct legal effects, are generally covert.

Moreover, the usual rigid structures of criminal proceedings are ignored for greater flexibility mainly in action, and the results of these activities have different and wider functions than merely repressive ones; their purpose is rather to provide the political decision-maker with all the elements necessary to carry out special operations abroad and in the National territory for the protection of $\mathrm{Na}$ tional Security, and to suppress and counteract enemy's espionage.

Dealing of Intelligence, therefore, implicitly is about secret services whose history is always a complex story and far from easy.

While the investigation works to ensure and restore the violated legal order, the role of Intelligence is synthesized in the Latin word salus rei publicae, as the task of Intelligence agencies is to look for, find, evaluate and provide the Government with useful information to make decisions in order to protect the country's security and National interests through the acquisition of information on possible threats.

A Nation is a center of political and economic interest whose balance is likely to threaten a host of potentially hostile subjects.

Intelligence, then, operates out of open dynamism and remains secret, reserved and obscure.

The reasons of such secrecy should be sought both in an institutional and inner resistance of the security system in getting acquainted with the "outside", 
and in citizens' lack of an ad-hoc institutional culture in general, and of security in particular.

It is not just the simple citizen to be excluded, but also those who work in the administration, at the highest levels of the political class, of the industry, of the economy.

Intelligence plays a key role in National Security; knowing and anticipating the decisions of a potential opponent can indeed be in many cases crucial to the survival of the Nation.

However, it is necessary to keep in mind that Intelligence is not a goal, but an instrument used to achieve goals that can indeed be public or private.

It can therefore be a tool to which the law entrusts certain missions or even a tool of private subjects that want to achieve specific goals on the free market.

Practically, if we want to understand what is the role played by Intelligence in the world we could refer to September 11, 2001.

Initially, after the Twin Towers' attack, many observers wondered how it could have been possible. The FBI had detailed information on the September 11 attacks and there was an intentional lack of initiative following the directives given.

One of the most intriguing aspects of Intelligence is then its combination with the political power, and often with the economic one, and, what happens when it fails.

The need for a truly efficient information system is a priority for all Nations.

Issues once considered low-profile such as the proliferation of unconventional and offensive weapons, major illicit trafficking and economic and financial crime, can integrate into a composite framework.

The process of remoulding and extending the assessments' roadmap, and modelling it in order to incorporate a wide-angle and a dynamic-differentiated profile of danger is a must.

A special impetus was put in the connection with other Government bodies, with the primary aim of an Intelligence that could be functional for the development of wide-ranging and useful strategies to prevention and response measures.

The information activity is based on the various security needs. National Security is a concept that refers to the idea of Nation not only in purely ethnic terms of nationality but in the wider sense of the defense as a center for political, economic, social and cultural imputations.

According to a simplistic vision of National Security, typical of an old constitutionalist doctrine, defense from external threats and the maintenance of internal order were of primary importance.

In contemporary Nations, international and regional organizations, legal entities under international law and an ever-increasing international structure of international relations made the system unprecedented and complex (Kaplan, 1967). 
The concept of National Security involves all the activities, citizens and tangible and intangible assets, culture and cultural identity.

The need for a National Intelligence is due to the fact that the possession and control of information are security factors.

National Security involves the entire National administrative and governmental structure as the search, formulation and definition of a real National interest is a crucial moment for strategies related to the concept of security.

Without a clear policy, it is not possible to run the system at its best.

The Nation must therefore be informed, preventing opponents and, if necessary, disinforming them, trying to maintain the information advantage to protect their National interests.

A Machiavellian affirmation but that is in the normal order of things.

In fact, this advantage can take on different forms: from the knowledge of the potential opponent's vulnerability, to their political intentions, and definition of goals and tactics.

As in poker or in chess it is important to understand the opponent's game without revealing one's own.

In this context, the action of Intelligence is similar to the military defense of the Nation.

The classic form of threat, the one that most affected the policy makers and Intelligence analysts, until the Second World War and much of the Cold War period, was that of territorial security.

Territory has always been the cause of contention between Nations, from Dynastic Wars to Colonial Expansion and Conquest.

The strategy was that of the military or the classical war in which opponents fought to have control and domination of the territory. In the new international scenario, however, we must face a meta-reality, which presupposes a threat on a different angle.

It was then necessary to elaborate new concepts of war related to the world of computer science and new technologies: softwar, netwar or cyberwar (Pierantoni \& Pierantoni, 1998), which, regardless of the physical territory and of the physical force, insist on information; therefore the military threat appears to be an element of potential danger but of lesser relevance.

Another type of threat is that to the stability. The so-called non-orthodox threat, diametrically opposed to the concept of traditional warfare, indicates the range of situations of internal or external origin, but still aimed at overthrowing its political and legal order.

The last form, and not less harmful, is the threat to national interests embedded in the economic threat.

More subdued and less apparent, the risk arising from this danger lies in the various countries inversely proportional to the potential and capacity of economical, banking and financial systems.

The last two forms of attack, non-orthodox threat and economic threat, are surrogate wars, based on offensive strategies, developed externally, coordinated 
or not, with the classic military instrument.

In the context of a surrogate war, we can mention: espionage, sabotage, subversion, terrorism, guerilla, interference, propaganda, influence, disinformation and separatism for the non-orthodox threat.

Under the economic threat are: illegal trafficking, technology transfer, economic penetration.

Identifying the various threats, we can define the possible attacks, the National defensive potential: the set of National resources, productive capacities, organization and the spiritual and immaterial potential.

All the economical, energetical, industrial, mining and agricultural resources are therefore the main fields of interest; especially the industrial, transport and commercial sectors and, last but not least, the potential of intellectuals, cultural, social, scientific and political domain.

Intelligence, therefore, is an instrument, a goal, that gives the possibility of assessing the National weaknesses in order to safeguard its security.

A double-cut knife, dangerous if used badly, operates from time immemorial, and evolves with the society itself and with its technical means.

\section{Conclusion}

In conclusion, the history of the world is a story that could be created through the battles that have been fought over the centuries.

War, in fact, is a constant.

At the beginning of the history of human civilization, however, when men were divided into tribes and then clans, the various leaders knew each other and the field of battle was known to both contestants.

Almost all knew about the enemy, given that few, or none, were the differences between "we" and "others"; the need to carry out information activities was therefore minimal.

Only when the conflicts began to affect increasingly numerous social groups, the war techniques became more complex.

The war then was not sole on the battlefield, but could also be won by skilled political maneuvers and based on the quantity and quality of the information that was collected on the enemy before the instant clash.

There was a need to move quickly and efficiently numerous groups of soldiers with some knowledge about, for example, the ground, the position of the enemy, its strength, and activity. Initially, the role of collecting the information was entrusted to soldiers, but over time, it was realized that they were not the ideal person to perform such kind of job.

On the battlefield, the militia was not able to penetrate the enemy files, and even if they could do it, they often turned out to be incapable of choosing which information to select and bring to the ground.

That was how a specially deputy staff was created and formed for the creation of an Information Service. 
Annibale, in the third century B.C., before his campaign against Rome, was the first general reported to infiltrate agents in Northern Italy in order to decide how to move with elephants and horses.

Similarly, the great Mongolian leader, Gengis Khan in the thirteenth century, used some explorers to carry out reconnaissances in Tibet on territories that were of interest. In order to conquer the country, some agents were infiltrated to spread rumors about his cruelty and audacity.

Even dating back from Annibale and Genghis Khan, however, the Hyksos (in ancient Egypt) showed interest in developing an information organization, using a variety of tools from torches to clasps, and employing special reconnaissance units, to search the ground and capture the prisoners in order to interrogate them.

In the Old Testament Moses sent some explorers to the land of Canaan and said to them: "Go up through the Negheb; then go to the mountain region and watch out what the people dress, whether strong or weak, whether small or large; how is the region, whether good or bad, and how they live in cities, countryside or fortified places; how is the soil, whether fertile or sterile, whether there are trees or not. Be courageous and bear fruit in the land".

Though the ancient populations were already aware of the importance of getting information about their enemies, the first written and documented testimony goes back to the Chinese general and philosopher Sun Tsu (Sun Zu) in the $4^{\text {th }}$ century B.C. who came to argue that the capability of achieving the goals was linked to the ability to make predictions; according to the Chinese philosopher the knowledge of the world is possible only through divination; information on natural science can be acquired through inductive reasoning, while universal laws are verifiable by mathematical calculations. The attitudes and abilities of the enemy can be acquired only and exclusively by the spies.

\section{References}

Colonna Vilasi, A. (2013). The History of MI6. Bloomington, IN: Authorhouse-Penguin.

Kaplan, M. (1967). System and Process in International Politics. Hoboken, NJ: Wiley \& Sons.

Pierantoni, F., \& Pierantoni, M. (1998). Combattere con le informazioni. Dalla geopolitica alla realtàvirtuale. Cemiss. Milano: Franco Angeli.

Rosenau, J. N. (1990). Turbulence in World Politics: A Theory of Change and Continuity. Princeton, NJ: Princeton University Press.

Sun Zu (2017). Wikipedia. http://it.wikiquote.org/wiki/Sun_Tzu 